\title{
RUÍNAS DA MEMÓRIA: AS METAMORFOSES DE MANAUS, EM DOIS IRMÃOS, DE MILTON HATOUM
}

\author{
RUINS OF MEMORY: THE METAMORPHOSES OF \\ MANAUS, IN DOIS IRMÃOS, BY MILTON HATOUM
}

\author{
Irlomar Ferreira Martins ${ }^{1}$ \\ Universidade do Estado do Amazonas \\ Marcos Frederico Krüger Aleixo ${ }^{2}$ \\ Universidade do Estado do Amazonas
}

\begin{abstract}
Resumo: Este estudo analisou como questões sócio-históricas sobre o povo e a cidade de Manaus estão representadas na obra Dois Irmãos (2006), do escritor Milton Hatoum. Apoiada na memória, a ficção hatouniana revisita o passado de Manaus, suscitando a história de um povo que no decurso dos anos foi vítima das graves consequências do projeto de modernidade instaurado em solo manauara. Nael, o narrador-personagem, trilha um percurso histórico e revela as metamorfoses pelas quais a sociedade e a capital amazonense passaram. Nesse processo, identificaram-se aspectos da crise da borracha que culminaram na criação da Cidade Flutuante, verificaram-se os impactos causados pelo projeto Zona Franca de Manaus, bem como os reflexos do militarismo na cidade por meio de personagens do romance. Com efeito, os ideais de progresso prestigiaram apenas a elite, enquanto a população tornou-se refém de inúmeros processos exploratórios.
\end{abstract}

Palavras-Chave: Memória; Manaus; Modernidade; Dois Irmãos.

1 Endereço eletrônico: irlomar91@gmail.com.

2 Endereços eletrônicos: marcosfrederico@uol.com.br e maleixo@uea.edu.br. 
Abstract: This study has analyzed how socio-historical questions about the people and the city of Manaus are represented in the work Dois Irmãos (2006), by the writer Milton Hatoum. Supported by the memory, the hatounian fiction reviews the past of Manaus, evoking the history of the people that through the years have been victim of hard consequences of the modernization process established in the manauara soil. Nael, the narrator-character, trails a historic path and reveals the metamorphoses of which the society and the Amazonian capital have passed. In this process, it is identified the aspects of the rubber crisis that culminated the creation of the Floating City, it is verified the impacts caused by the Zona Franca de Manaus project, as well as the reflexes of the militarism in the city by characters of the novel. As an effect, the ideals of progress had honored the higher class only, while the popular class has become a hostage of uncountable exploratory processes.

Keywords: Memory; Manaus; Modernity; Dois Irmãos.

\section{INTRODUÇÃO}

Não se pode negar que a produção literária do escritor amazonense Milton Hatoum se situa entre as mais destacadas na contemporaneidade da literatura brasileira, posto que suas obras já transpuseram os limites regionais e se tornaram universais. Em suas narrativas, Hatoum explora as especificidades da região amazônica, buscando, entre outros aspectos, resgatar questões sóciohistóricas que ficaram à margem da história, camufladas pelos ideais de progresso instaurados na região Norte, a partir de meados do século XX. Nesse viés, Manaus torna-se um espaço crucial, visto que neste lugar é onde estão engendrados os enredos da ficção hatouniana.

Como elemento peculiar da estética de Hatoum, as histórias são ancoradas pela memória, pilastra de suas narrativas, capaz de tornar passado, presente e futuro entrelaçados, indissociáveis e em permanentes diálogos, tendo em vista que "a memória inventa, mesmo quando quer ser fiel ao passado" (HATOUM, 2006, p. 67). Tal singularidade na escrita hatouniana é objeto de inúmeras pesquisas no âmbito acadêmico e razão pela qual alguns críticos literários alcunham o escritor manauara de o arquiteto da memória ${ }^{3}$.

3 Milton Hatoum é formado em Arquitetura pela (FAU/USP) e por suas narrativas serem caracterizadas pelo alicerce da memória, o escritor recebeu a referida alcunha. 
Por meio das nuances memorialísticas, o ficcionista revisita o passado histórico de Manaus em suas obras e traz à tona temáticas que vão muito além da ficção literária, pois evocam a história e a identidade de um povo que ao longo dos anos foi socialmente marginalizado, excluído do progresso e vítima das graves consequências provocadas pelo projeto de modernidade na capital amazonense, provenientes da camada capitalista.

Assim, a presente pesquisa propõe analisar como a memória histórica da cidade de Manaus está representada no romance Dois Irmãos (2006), de Milton Hatoum, e como tal representação resgata questões sócio-históricas acerca da população manauara.

Com efeito, este estudo envereda pelas constantes metamorfoses da metrópole do Amazonas, as quais se desdobram em três importantes fases no decorrer do romance: a crise do ciclo da borracha, o advento da Zona Franca e a instalação da ditadura militar. Por meio dos meandros da memória, o narrador e personagem Nael trilha esse percurso histórico, revelando as transformações sociais, políticas e econômicas pelas quais a comunidade e a capital amazonense passaram. Deste modo, a narrativa que enfoca os intermináveis conflitos entre os gêmeos Yaqub e Omar, filhos do casal Halim e Zana, imigrantes libaneses que se instalaram em Manaus no início do século XX, também expõe no bojo do enredo os aspectos da memória histórica da cidade.

Dessa forma, na primeira parte pretende-se destacar a importância da memória na narrativa hatouniana, como também aspectos decorrentes do ciclo da borracha, com ênfase nos ex-seringueiros e na criação da Cidade Flutuante. Na segunda parte, analisar-se-ão as consequências provocadas pela implantação da Zona Franca de Manaus, principal símbolo da modernidade, culminando com o último estágio desse processo, que se consolida com a tomada da cidade portuária pelo regime militar, foco da discussão da última parte. 
Ademais, a pesquisa constitui-se relevante pela inclusão da Literatura Amazonense no cenário dos estudos acadêmicos, visando expandir e promover essa tão rica, fértil e singular escrita literária. Espera-se que este estudo possa contribuir para futuros trabalhos científicos, sobretudo aos que se debruçarão nessa vertente literária, versem sobre traços da memória inseridos no romance Dois Irmãos, bem como nas características do escritor Milton Hatoum.

\section{O ALICERCE DA MEMÓRIA NA FICÇÃO HATOUNIANA}

Conforme já mencionado antes, no universo ficcional de Milton Hatoum, a memória é o fio condutor de suas narrativas. O diálogo entre autor e seus narradores se dá na relação com o passado, pois ao mesmo tempo em que faz um trabalho de exploração de sua memória pessoal, a narrativa é também desenvolvida a partir da memória do narrador, realizando, assim, um duplo movimento. Assim, no bojo da memória, estão os dramas humanos como tema central e, no mote da narrativa, as famílias e casas que se desfazem. Os mundos retratados na literatura hatouniana são mundos arruinados pela ideologia capitalista, tendo a cidade de Manaus como personagem ativa e espaço privilegiado de suas histórias.

Pelos fios da memória, o passado e o presente se conectam por meio de recorrentes diálogos e "esses tempos se misturam e se contaminam da textura íntima um do outro" (MAQUÊA, 2010, p. 36) dentro da narrativa. A partir desse encontro mediado pela memória, os narradores de Hatoum suscitam questões sócio-históricas que rompem as fronteiras da ficção literária. Histórias de um passado não tão distante, caracterizado pela ruína econômica de uma cidade e permeado de personagens marcados pela submissão, reféns das mais variadas formas de exploração. 
Reportando-se ao papel imprescindível da memória em seus romances, o autor considera que ela é a única forma desafiadora de prestar contas com o passado, cujo "ponto de partida são essas ruínas, e a ficção é uma tentativa de imaginar a sua história, reconstruí-la e retornar ao que já não existe mais" (HATOUM apud CRISTO, 2007, p. 25). A partir de tal afirmação, considera-se a memória como fonte inesgotável para a literatura do supracitado escritor, uma vez que esta se fundamenta em experiências passadas, que por meio do dinamismo do tempo se tornam indubitavelmente mutáveis.

Nesse sentido, em A escrita nômade do presente: literaturas de língua portuguesa, Vera Maquêa (2010, p. 28) analisa o conceito de memória e sua estreita relação com a literatura, indo buscar na filosofia grega a sua origem, ou seja, na "poesia do começo". Para a autora,

[...] na raiz da memória está a poesia, a narrativa, a sedução de contar uma história. Na origem da literatura está a qualidade religiosa da memória como aquilo que vincula o presente dos homens à sua ancestralidade, conferindolhes humanidade e capacidade de viver o futuro em perspectiva.

Se a narrativa está inserida na "raiz da memória", convém ressaltar que o solo literário de Hatoum se fertiliza nessa raiz, posto que suas obras resgatam a história de um povo, forjam identidades sociais, bem como descrevem um passado inglório que ainda se reflete no presente. Em Dois Irmãos, o narrador parece dialogar com tal concepção na seguinte passagem: “Omissões, lacunas, esquecimento. $\mathrm{O}$ desejo de esquecer. Mas eu me lembro, sempre tive sede de lembranças, de um passado desconhecido, jogado sei lá em que praia do rio" (HATOUM, 2006, p. 67). Dessa forma, sobre o projeto literário hatouniano convém dizer que "toda consciência do passado está fundada na memória" (LOWENTHAL, 1998, p. 75), sendo esta o elemento que permite a conexão entre espaços de tempo distantes na história. 
Além disso, na obra História e Memória, Le Goff (1990, p. 476) preconiza que “a memória é um elemento essencial do que se costuma chamar de identidade, individual ou coletiva, cujas buscas são uma das atividades fundamentais dos indivíduos e das sociedades de hoje, na febre e na angústia". Em consonância com esse pensamento, as transformações da cidade de Manaus comungam com a construção de Nael, narrador-personagem, que busca por meio do fluxo de memória montar as peças de um quebra-cabeça, a fim de desvendar os segredos e mistérios que estão por detrás de sua identidade, oculta e fragmentada pela omissão de um passado: “Eu não sabia nada de mim, como vim ao mundo, de onde tinha vindo. A origem: as origens" (HATOUM, 2006, p. $54)$.

Em Dois Irmãos (2006), cuja primeira edição foi publicada em 2000, Nael procura descobrir em qual dos gêmeos, Omar e Yaqub, da família dos imigrantes libaneses, está sua identidade paterna. Para tanto, recorre, sobretudo, às memórias do patriarca Halim e aos relatos esparsos de sua mãe Domingas, uma índia nascida no interior do Amazonas que se torna empregada do lar libanês. Nael desenvolve o enredo a partir do quarto construído nos fundos do quintal da casa, pois é o herdeiro bastardo daquele núcleo, visto pela matriarca Zana apenas "como rastro dos filhos dela" (HATOUM, 2006, p. 28).

A partir de tal investigação, o narrador apresenta um percurso histórico da capital amazonense, que perpassa o fim do ciclo da borracha, a implantação da Zona Franca de Manaus (ZFM) e a tomada da cidade pelo governo militar no desfecho do romance. Grosso modo, a história de Manaus é exposta pelo "olhar de um agregado de descendência indígena no seio da família imigrante libanesa, que descreve os processos de urbanização e modernização da cidade de Manaus, ambos vistos por ele como dolorosos e melancólicos" (BORGES, 2010, p. 18). Com efeito, pelo alicerce da memória, ele também desvela uma Manaus em 
metamorfoses, cuja identidade se (re)configura ao longo dos anos para ajustar-se aos ditames capitalistas.

Dessa forma, no romance em estudo, o passado da capital amazonense é revisitado e de acordo com as palavras do narrador, "nenhum passado é anônimo" (HATOUM, 2006, p. 125). Vale salientar, no entanto, que “o passado é uma imagem mutilada, torso: um misto indissociável de lembrança e trabalho do tempo, esquecimento" (SELIGMANN-SILVA, 2003, p. 404). Ainda assim, na narrativa do supramencionado romance, Milton Hatoum parece recorrer às nuances da memória não somente para constituir o enredo da trama, mas também para expor "a história do cotidiano atravessada pela história de gente sem história" (MAQUEA, 2010, p. 58), gente que continuou sendo explorada após o fim do colonialismo, sob outras formas de colonização.

\section{A CIDADE FLUTUANTE: UM POVO À MARGEM DA HISTÓRIA}

$\mathrm{Na}$ arquitetura literária de Dois Irmãos, Milton Hatoum traz à tona o sôfrego processo de exploração a que os seringueiros-sertanejos se submeteram durante o ciclo da borracha. Com a decadência desse período, esses ribeirinhos migraram para a cidade e tiveram de construir casas sobre troncos ${ }^{4}$ em igarapés de bairros periféricos, vivendo em "um mundo escondido, cheio de seres que improvisavam tudo para sobreviver" (HATOUM, 2006, p. 59). Nascia dessa forma a "Cidade Flutuante".

No romance hatouniano, o narrador refere-se a esses seringueiros como "os soldados da borracha", conforme se evidencia no seguinte trecho:

Halim [...] vendia de tudo um pouco aos moradores dos Educandos, um dos bairros mais populosos de Manaus, que crescera muito com a chegada dos

\footnotetext{
4 Na narrativa hatouniana, troncos refere-se àquelas estruturas de madeiras que são os alicerces das casas flutuantes, também conhecidas no interior do Amazonas como boias.
} 
soldados da borracha, vindos dos rios mais distantes da Amazônia. Com o fim da guerra, migraram para Manaus, onde ergueram palafitas à beira dos igarapés, nos barrancos e clarões da cidade. Manaus cresceu assim: no tumulto de quem chega primeiro. (HATOUM, 2006, p. 32)

É com a expressão "tumulto de quem chega primeiro" que o narrador revela o espaço desses flagelados, que a cada dia recebia um contingente de ribeirinhos, os quais improvisavam seus lares sem quaisquer infraestruturas nas beiradas dos igarapés. Vivendo em condições paupérrimas, segundo os relatos do narrador, esses indivíduos formaram o bairro do Educandos, "o bairro anfíbio do centro de Manaus [...], o labirinto de casas erguidas sobre troncos" (HATOUM, 2006, p. 90).

Com o demasiado crescimento provocado pela aglutinação dos nordestinos-seringueiros e caboclos nativos, o Educandos se tornara um dos bairros mais populosos de Manaus, o abrigo das camadas populares e, consequentemente, o símbolo legítimo de exclusão social, tendo em vista que neste espaço se registravam inúmeras mazelas sociais. Em dado momento, evocando as memórias de sua infância, Nael descreve a difícil rotina dos habitantes da Cidade Flutuante:

O labirinto de casas erguidas sobre troncos fervilhava: um enxame de canoas navegava ao redor das casas flutuantes, os moradores chegavam do trabalho, caminhavam em fila sobre as tábuas estreitas, que formam uma teia de circulação. Os mais ousados carregavam um botijão, uma criança, sacos de farinha; se não fossem equilibristas, cairiam no Negro. Um ou outro sumia na escuridão do rio e virava notícia. (HATOUM, 2006, p. 90)

Depreende-se do fragmento acima, a triste realidade desses moradores, sujeitos anônimos, residindo em um espaço urbano desprestigiado, expostos ao cheiro do lodo, à sujeira e enfrentando diversos perigos para sobreviver. Definitivamente, “o ciclo da borracha levara as glórias da modernização apenas para uma pequena parcela da sociedade amazonense" (BORGES, 2010, p. 27). 
Nesta perspectiva, Frederico Lima (2014) destaca o longo período de infortúnios que estes trabalhadores enfrentaram desde os seringais até a estada em espaços urbanos. Conforme o escritor, no final da fase gomífera os soldados da borracha trilharam diversos caminhos, vinculando-se em terras devolutas à margem dos rios ou peregrinando pelas cidades oferecendo-se a empregos de baixa remuneração. Assim, esses sobreviventes saíam de suas terras natais com o coração imbuído de sonhos e de esperança em um futuro promissor, porém a realidade vigente contrastava bruscamente os ideais que os fizeram desbravar a região amazônica.

Em se tratando disso, em Judas-Asvero ${ }^{5}$, Euclides da Cunha registra as condições sombrias dos seringueiros que povoavam as margens ribeirinhas da Amazônia. O episódio, que originou-se de uma viagem do escritor às cabeceiras do rio Purus no início do século XX, enfatiza o total desprezo social do sertanejoseringueiro, que movido por "uma ambição maldita que o levou àquela terra", passou a viver "impassível e mudo, estoicamente, no grande isolamento de sua desventura" (CUNHA, 2011, p. 72), como escravo para sustentar os barões da borracha.

Desse modo, em Judas-Asvero, o ficcionista brasileiro critica os ideais de modernidade preconizados pela elite amazonense, uma vez que esse processo excluía aqueles seringueiros que estavam às margens do rio Purus e, consequentemente, à margem da história. Tal olhar crítico também se observa quando o boneco (o Judas), esculpido pelo seringueiro em pleno Sábado de Aleluia, é solto à deriva no rio, tornando-se, dessa forma, uma metáfora desses retirantes, que após o fim do ciclo da borracha migraram para as grandes metrópoles em busca de sobrevivência.

5 Judas Asvero é um episódio que integra o livro À Margem da História, de Euclides da Cunha. Está também disponível em Amazônia - um paraíso perdido (2011), da Editora Valer. 
Com suas "vidas arruinadas", nas palavras do narrador de Dois Irmãos, morando em casas de palafitas dos bairros periféricos de Manaus e sobrevivendo em péssimas condições, os ex-seringueiros apenas continuaram seus fluxos de miséria e penúria oriundos dos seringais, sendo, portanto, reféns de outras formas de exploração. O progresso não os alcançara e "o futuro ou a ideia de um futuro promissor, dissolvia-se no mormaço amazônico" (HATOUM, 2006, p. 96).

Mediante o exposto, observa-se neste período um malfadado projeto de modernidade, prestigiando apenas os interesses da elite manauara, a qual sempre desfrutou do trabalho dos explorados/escravizados. À luz desta análise, em A Invenção da Amazônia, a escritora Neide Gondim (2007, p. 258) corrobora tal perspectiva ao afirmar que "na dança frenética da modernidade escravizam-se homens, fortunas crescem com a mesma rapidez com que desaparecem, tangidas pelas ações das indústrias da borracha".

\section{ECOS DA MODERNIDADE: OS IMPACTOS DA ZFM NA POPULAÇÃO MANAUARA}

Na tessitura da narrativa Dois Irmãos, as lembranças de Nael apresentam Manaus passando por constantes transformações com o êxtase de progresso promovido pelas ações do governo militar. Neste contexto, o projeto da Zona Franca de Manaus não só se torna o principal símbolo da modernidade, como também atrai o olhar de investidores para a capital amazonense. Com efeito, Manaus passa a acolher imigrantes indianos, coreanos, chineses, e o centro da cidade encontra-se "cheio de lojas que se abriam da noite para o dia" (HATOUM, 2006, p. 173).

Essa efervescência pelo moderno em solo manauara, motivadas sobretudo pela inauguração da capital Brasília, bem como pelo notório progresso em São Paulo, também promovera mudanças significativas no recinto da família libanesa. Entusiasmada pela ideia de empreendedorismo e movida pelas mãos e 
palavras de Yaqub, em poucos meses, Rânia transforma radicalmente a loja de seu pai, antecipando a euforia econômica que não iria tardar.

Rânia recebia as amostras, escolhia os tecidos, as camisetas, carteiras e bolsas. Quando Halim se deu conta, já não vendia quase nada do que sempre vendera: redes, malhadeiras, caixas de fósforo, terçados, tabacos de cordas, iscas para corricar, lanternas e lamparinas. Assim, ele se distanciava das pessoas do interior, que antes vinham à sua porta, entravam na loja, compravam, trocavam ou simplesmente proseavam, o que para Halim dava quase no mesmo. Agora a fachada da loja exibia vitrines, e pouca coisa restava que lembrasse o antigo armarinho a menos de duzentos metros da praia do Negro. (HATOUM, 2006, p. 99)

A partir do fragmento acima é possível perceber que, assim como há severas mudanças na cidade, a casa dos imigrantes libaneses também sofre um processo de mutação no transcorrer dos anos, desvencilhando-se de objetos arcaicos e passando a receber novas molduras e novas facetas, como símbolo fiel da chegada de um novo tempo. Ou seja, concomitantemente, cidade e casa são mutiladas e regidas pelos impactos da era moderna.

Com o advento da ZFM, “Manaus crescia muito com suas indústrias e seu comércio" (HATOUM, 2006, p. 169), porém os impactos desse crescimento se refletiam nas ruas e, principalmente, nas camadas baixas da população manauara, sempre vítimas dos anseios da esfera hegemônica. Em íntegro diálogo com esta concepção, em Globalização: As consequências humanas (1999), Zygmunt Bauman ressalta que a chegada do novo, do progresso, atinge distintamente as classes sociais consideradas altas e baixas. Segundo o sociólogo, enquanto os sujeitos da elite podem escolher os seus destinos de acordo com o que lhes são mais aprazíveis, os que estão embaixo, frequentemente são expulsos do lugar em que gostariam de ficar e se eles não se retiram, o lugar muitas vezes é puxado como um tapete sob seus pés e, se porventura, puserem os pés na estrada, mais uma vez ficarão nas mãos de outros, posto que em nenhum lugar serão autorizados a armar suas tendas. 
Assim, se por um lado os ares da modernidade atraíram para a região amazônica empreendedores como a personagem Rochiram, um indiano extremamente movido pelo capital, que morava “em pátrias provisórias" (HATOUM, 2006, p.169) sempre à procura de negócios, por outro, na população local havia indivíduos semelhantes à personagem Adamor (o Perna de Sapo), o mateiro e peixeiro ambulante, que no fim da narrativa tornou-se coveiro e sem mais perspectivas na vida "embrenhou-se no traçado de becos de Manaus, ergueu uma palafita e mofou no fedor dos pauís" (HATOUM, 2006, p. 125). Diante das disparidades socioeconômicas presentes na cidade, representadas na narrativa hatouniana pelas duas personagens, convém salientar que "o preço do progresso estaria marcado nas lutas e nas fisionomias dos excluídos. Um olhar sobre eles permitirá revelar uma Manaus diferenciada, não tão bela ou culta, mas também sombria, pobre e conflituosa" (PINHEIRO, 2003, p. 47).

\subsection{As ruínas da cidade flutuante}

Nesse processo de modernização na metrópole do Amazonas, antigos sobrados, como também bares e restaurantes, foram destruídos, cedendo espaço à construção de fábricas industriais. Além disso, igarapés foram soterrados, bairros periféricos de Manaus demolidos, a fim de promover a criação da ZFM. Assim, a "Cidade Flutuante" foi destruída, abrindo território para o projeto de expansão da Zona Franca, o qual carregava consigo a euforia da modernidade.

Em Dois Irmãos, o narrador descreve o fim da Cidade Flutuante com um olhar estarrecedor diante das atrocidades do governo.

Halim [...] estava ao lado do compadre Pocu, cercado de pescadores, peixeiros, barqueiros e mascates. Assistiam, atônitos, à demolição da Cidade Flutuante. Os moradores xingavam os demolidores, não queriam morar longe do pequeno porto, longe do rio. Halim balançava a cabeça, revoltado, vendo todas aquelas casinhas serem derrubadas. [...] Ele chorou muito 
quando viu as tabernas e o seu bar predileto, A Sereia do Rio, serem desmantelados a golpes de machado. [...] Tudo se desfez num só dia, o bairro todo desapareceu. (HATOUM, 2006, p. 158-9)

A partir do relato do narrador, notam-se no universo ficcional de Hatoum marcas provocadas pelos processos de modernização da cidade, os quais foram promovidos por uma política excludente, que privilegiou determinada esfera social em detrimento de outras.

Conforme se constata no fragmento acima, “os pobres perderam as antigas estruturas existentes, afastados, compulsoriamente, da área central da cidade, pela política de demolição de suas casas, para atender as necessidades de reedificação e embelezamento da capital" (DIAS, 2007, p. 145). Acerca dessas transformações ocorridas em Manaus, o próprio Milton Hatoum afirma: “A Zona Franca foi uma violência para a cidade. Para os valores culturais, para os costumes, para o espaço urbano. Também para a relação da cidade com a floresta, porque antes a natureza pertencia à cidade. Depois aboliram a floresta da cidade, destruíram muitas coisas." (HATOUM apud BORGES, 2010, p. 85).

Com efeito, após a derrocada da Cidade Flutuante, ao caminhar pelas ruas, Nael registra de forma perplexa o estado deplorável da cidade e de seus habitantes desabrigados:

Eu acabara de dar minha primeira aula no liceu onde havia estudado e vim a pé para cá, sob a chuva, observando as valetas que dragavam o lixo, os leprosos amontoados, encolhidos debaixo dos oitizeiros. Olhava com assombro e tristeza a cidade que se mutilava e crescia ao mesmo tempo, afastada do porto e do rio, irreconciliável com seu passado. (HATOUM, 2006, p. 197)

As mudanças na cidade a tornam "mutilada e irreconciliável com o seu passado", visto que os novos bairros afastaram a população ribeirinha do rio Negro. O local que outrora significava a principal fonte de renda dos ribeirinhos, 
nesta nova fase passou a receber navios da Booth Line ${ }^{6}$ lotados de "caixas de produtos eletrônicos" (HATOUM, 2006, p. 180) que eram distribuídas no comércio da ZFM. Neste contexto de metamorfoses, o escritor Márcio Souza (2010, p. 180) elucida que “a Zona Franca, com sua estratégia ligada às multinacionais, ao comércio de importação [...], abre ainda mais a região ao exterior, promovendo uma economia dependente, altamente espoliadora e prejudicial". Como consequência disso, muitos daqueles que perderam as suas antigas estruturas, passaram a ocupar os espaços urbanos vivendo aglomerados como "mendigos leprosos", de acordo com as palavras do narrador.

Nesse sentido, em conformidade com Oliveira (2003), nota-se que a cidade era sempre apresentada como um espaço em que só a elite tinha rosto e se destacava. Os pobres eram "ninguém", não eram considerados nessa espacialização. A cidade moderna, a qual respirava os ares do progresso, não tinha lugar para eles.

\subsection{Os reflexos do militarismo: medo, repreensão e sombras na cidade de Manaus}

Nos últimos capítulos, o romance hatouniano não só expõe as graves consequências do projeto de modernidade na cidade, mas também apresenta, como pano de fundo, o estilo sombrio e autoritário do governo militar durante este processo. Os frequentes atos de repreensão e violência que caracterizaram esta gestão fez a cidade se tornar deserta, assim como despertou o sentimento de revolta, medo, instabilidade e de submissão na população amazonense.

Nesta fase, por meio do olhar de Nael, verifica-se uma cidade censurada, cercada por militares, uma vez que "as escolas e os cinemas tinham sidos fechados, lanchas da Marinha patrulhavam a baía do Negro, e as estações de

6 A Booth Line era uma companhia de navegação inglesa, que se notabiliza no romance hatouniano, principalmente, pelo transporte de mercadorias internacionais à capital amazonense. 
rádio transmitiam comunicados do Comando Militar da Amazônia" (HATOUM, 2006, p. 149). Em outro momento, o patriarca Halim também reclama da invasão militar aos locais citadinos: “Eles estão em toda parte [...]. Até nas árvores dos terrenos baldios a gente vê uma penca de soldados" (HATOUM, 2006, p. 147).

Outrora, durante um diálogo com Yaqub, mais uma vez Nael deixa transparecer o sentimento de medo e o caos que tomara conta da cidade: "Eu não queria sair de casa, não entendia as razões da quartelada, mas sabia que havia tramas, movimentos de tropas, protestos por toda parte. Violência. Tudo me fez medo" (HATOUM, 2006, p. 149). Havia, portanto, um forte clima de tensão e de hostilidade permeando a capital, propiciando assim mais incertezas para os habitantes manauaras.

Em confluência com a narrativa de Hatoum, citando Ianni (2000), Seráfico e Seráfico (2005), destacamos que, nesse período, os grupos sociais dominantes (aqui representado pelo militarismo) comportavam-se como conquistadores, colonizadores e desfrutadores. Estavam inclinados a associarem-se com monopólios, organizações, corporações, conglomerados, pois consideravam o país, a sociedade nacional e o povo local como um território de negócios, pastagem de lucro.

Assim sendo, todo e qualquer movimento ou cidadão que afrontasse ou representasse ameaça para tais ideais, estaria sujeito às mais absurdas formas de repreensão. Em Dois Irmãos, a personagem Antenor Laval sente na pele o caráter insano e agressivo deste governo:

Foi humilhado no centro da praça das Acácias, esbofeteado como se fosse um cão vadio à mercê da sanha de uma gangue feroz. Seu paletó branco explodiu de vermelho e ele rodopiou no centro do coreto, as mãos cegas procurando um apoio, o rosto inchado girando para o sol, o corpo girando sem rumo, cambaleando, tropeçando nos degraus da escada até tombar na beira do lago da praça. [...] Laval foi arrastado para um veículo do Exército, e [...] dois dias depois soubemos que Antenor Laval estava morto. (HATOUM, 2006, p. 142) 
Laval era poeta e professor de literatura francesa de Omar e posteriormente de Nael. No entanto, as razões pelas quais ele sofrera as agressões que culminaram em sua morte justificavam-se, sobretudo, pelo fato dele, possivelmente, ter sido um "militante vermelho, dos mais afoitos, chefe dos chefes, com passagem por Moscou" (HATOUM, 2006, p. 144), ou seja, era contrário e um crítico ferrenho do governo militar. Por ser amigo e admirador das concepções políticas do poeta, Omar também se depara com as atitudes coercitivas dos policiais: “Omar [..] caiu de costas e foi puxado, arrastado até a viatura. Rânia correu ao encontro do irmão, viu no rosto dele um fio vermelho e grosso que a água não apagava [...] e eu intuí que a sua amizade com Antenor Laval era uma forma de condenação política." (HATOUM, 2006, p. 193-194).

As agressões sofridas tanto por Laval quanto por Omar revelam, em linhas gerais, que durante este período "os movimentos favoráveis ao restabelecimento dos direitos humanos, a favor da anistia, pelo fim da tortura, da censura, [...] eram tidos como movimentos que pretendiam estabelecer mudanças em detrimento do regime; o que não seria admitido, segundo os seus condutores" (REZENDE, 2013, p. 181). Assim, qualquer manifestação política contra os atos praticados pelo regime militar era considerada uma ameaça, uma atitude rebelde, uma forma de subverter a ordem e deveria, portanto, ser repelida de maneira veemente. Com efeito, a capital que anteriormente recebera a alcunha de "Paris dos Trópicos", fora transformada numa cidade sombria, em ruínas, irreconciliável não só com o seu passado, mas também sem perspectivas de um futuro promissor.

\section{CONSIDERAÇÕES FINAIS}

A obra Dois Irmãos permite ao leitor conhecer um traçado histórico da cidade de Manaus situado entre 1910 até o final dos anos 60. Nesse período está 
presente o fim do ciclo da borracha, com a presença dos sertanejos-seringueiros na capital amazonense, o processo de modernidade representado pela Zona Franca de Manaus, concomitante com a consolidação da ditadura militar.

Neste percurso, observou-se que, ancorada pelos fios da memória, a narrativa de Milton Hatoum transfigura à ficção literária a triste realidade da cidade e do povo amazonense, denunciando as disparidades socioeconômicas vigentes no decorrer do eufórico projeto de modernização. Além disso, identificou-se que o universo literário do escritor manauara dá voz a indivíduos silenciados na história, os quais jamais puderam expressar a dor e sofrimento a que sempre estiveram submetidos. Indivíduos que foram marginalizados socialmente, esquecidos no espaço e no tempo, privados de quaisquer meios de progresso.

É neste contexto que se enquadram os ex-seringueiros, os soldados da borracha, que ao final da fase gomífera migraram para a capital do Amazonas e apenas continuaram seus ciclos de miséria, habitando em lugares paupérrimos e enfrentando condições desumanas a fim de sobreviverem. Dessa forma, em conformidade com as palavras de Pinheiro (2003), o mesmo processo que deu a Manaus um aspecto moderno foi também o mesmo que reforçou em seu interior práticas de exclusão sobre uma imensa parcela da população, fazendo-a sentir fortemente o peso da opressão, da miséria e da fome.

Pelas reminiscências do narrador, constatou-se que a inserção da modernidade em solo manauara configurou-se de forma dolorosa e excludente, prestigiando apenas os interesses daqueles que detinham o poder socioeconômico, como o indiano Rochiram, por exemplo, empresário movido pelos negócios, considerado a personificação de um capitalismo perverso, explorador. Por outro lado, na população amazonense havia figuras como Adamor, Domingas e Nael, aos quais, assim como aos ex-seringueiros, tudo fora negado, inclusive a autêntica identidade. 
Ademais, verificou-se na obra hatouniana, sobretudo pelas agressões ao professor Antenor Laval, o retrato fiel do caráter autoritário e agressivo do governo militar, o qual não mensurava limites para impor suas concepções. A gestão que teve início em 1964 perdurou até meados dos anos 80, configurando um clima de medo, hostilidade e incertezas não só na metrópole do Amazonas, mas também em todas as demais capitais do país durante esse tenso período.

É por meio desses e outros aspectos pertencentes ao romance Dois Irmãos, que a produção literária do amazonense Milton Hatoum tem cruzado as fronteiras regionais e se tornado literatura universal.

\section{REFERÊNCIAS}

BAUMAN, Zygmunt. Globalização: as consequências humanas. Tradução Marcus Penchel. Rio de Janeiro: Jorge Zahar Ed., 1999.

BORGES, Kárita. A. de Paula. Dois irmãos de Milton Hatoum: um olhar que vem do Norte. 2010. 106 f. Dissertação (Mestrado em Literatura) - Instituto de Letras, Universidade de Brasília, $\quad 2010 . \quad$ Brasília, Disponível em: http://repositorio.unb.br/bitstream/10482/8268pdf. Acesso em: 21 jun. 2020.

CRISTO, Maria da Luz Pinheiro (Org.). Arquitetura da memória: ensaios sobre os romances Relato de um certo oriente, Dois irmãos e Cinzas do Norte de Milton Hatoum. Manaus: Editora da Universidade Federal do Amazonas UNINORTE, 2007.

CUNHA, Euclides da. Judas-asvero. In: Amazônia: um paraíso perdido. 2. ed. Manaus: Valer, 2011.

DIAS, Edinea Mascarenhas. A ilusão do fausto - Manaus 1890-1925. 2. ed. Manaus: Valer, 2007.

GONDIM, Neide. A invenção da Amazônia. 2. ed. Manaus: Valer, 2007.

HATOUM, Milton. Dois irmãos. São Paulo: Companhia das Letras, 2006.

IANNI, Octavio. O declínio do Brasil-nação. Estudos avançados, São Paulo, v. 14, n. 40, p. 51-58, dez. 2000. Disponível em: https://www.revistas.usp.br/eav/article/view/9543. Acesso em: 06 de jul. 2020.

LE GOFF, Jacques. História e memória. Tradução Bernardo Leitão. Campinas: Editora da UNICAMP, 1990.

LIMA, Frederico A. de Oliveira. Soldados da borracha: das vivências do passado às lutas contemporâneas. Manaus: Valer, 2014. 
LOWENTAL, David. Como conhecemos o passado. Tradução Lúcia Haddad. Projeto História, São Paulo, v. 17, p. 63-201, jul./dez. 1998.

MAQUÊA, Vera. A escrita nômade do presente: literaturas de língua portuguesa. São Paulo: Arte \& Ciência, 2010.

OLIVEIRA, José Aldemir de. Manaus de 1920-1967: A cidade doce e dura em excesso. Manaus: Valer, 2003.

PINHEIRO, Maria Luiza Ugarte. A cidade sobre os ombros: trabalho e conflito no porto de Manaus (1899-1925). 2. ed. Manaus: Edua, 2003.

REZENDE, Maria José de. A ditadura militar no Brasil: repressão e pretensão de legitimidade - 1964-1984. Londrina: Eduel, 2013.

SELIGMANN-SILVA, Márcio (org.). História, memória, literatura: o testemunho na era das catástrofes. Campinas: Editora da UNICAMP, 2003.

SERÁFICO, José; SERÁFICO, Marcelo. A Zona Franca de Manaus e o capitalismo no Brasil. Estudos avançados, São Paulo, v. 19, n. 54, p. 99-113, ago. 2005. Disponível em: http://www.scielo.br/scielo.php?pid=S010340142005000200006\&-script=sci_arttext.

Acesso em: 04 jul. 2020.

SOUZA, Marcio. A expressão amazonense: do colonialismo ao neocolonialismo. 3. ed. Manaus: Valer, 2010.

Nota do editor:

Artigo submetido para avaliação em: 11 de janeiro de 2021.

Aprovado em sistema duplo cego em: 07 de julho de 2021 